Article

\title{
Ursolic Acid Inhibits Collective Cell Migration and Promotes JNK-Dependent Lysosomal Associated Cell Death in Glioblastoma Multiforme Cells
}

\author{
Gillian E. Conway ${ }^{1,2,3, *(\mathbb{D})}$, Deimante Zizyte ${ }^{1}$, Julie Rose Mae Mondala ${ }^{1} \mathbb{D}$, Zhonglei He ${ }^{1,2}$, Lorna Lynam ${ }^{1}$, \\ Mathilde Lecourt ${ }^{1}$ (D), Carlos Barcia ${ }^{4}$, Orla Howe ${ }^{2,5} \mathbb{D}$ and James F. Curtin ${ }^{1,2, * \mathbb{D}}$
}

1 School of Food Science and Environmental Health, Technological University Dublin, D01 HV58 Dublin, Ireland; deimante.zizyte@tudublin.ie (D.Z.); julie.mondala@tudublin.ie (J.R.M.M.); zhonglei.he@tudublin.ie (Z.H.); lorna195@live.ie (L.L.); lecourt.mathilde31@gmail.com (M.L.)

2 Environmental Sustainability and Health Institute (ESHI) and FOCAS Research Institute, Technological University Dublin, D08 CKP1 Dublin, Ireland; orla.howe@tudublin.ie

3 In-Vitro Toxicology Group, Institute of Life Science, Swansea University Medical School, Swansea University, Singleton Park, Swansea SA2 8PP, UK

4 Institut de Neurociències, Department of Biochemistry and Molecular Biology, School of Medicine, Universitat Autònoma de Barcelona, 08193 Bellaterra, Spain; carlos.barcia@uab.es

5 School of Biological Sciences and Health Sciences, Technological University Dublin, D08 NF82 Dublin, Ireland

* Correspondence: gillian.conway@swansea.ac.uk (G.E.C.); james.curtin@tudublin.ie (J.F.C.)

check for updates

Citation: Conway, G.E.; Zizyte, D.; Mondala, J.R.M.; He, Z.; Lynam, L.; Lecourt, M.; Barcia, C.; Howe, O.; Curtin, J.F. Ursolic Acid Inhibits Collective Cell Migration and Promotes JNK-Dependent Lysosomal Associated Cell Death in Glioblastoma Multiforme Cells. Pharmaceuticals 2021, 14, 91. https:// doi.org/10.3390/ph14020091

Academic Editor: Paulo Santos Received: 16 December 2020

Accepted: 20 January 2021

Published: 26 January 2021

Publisher's Note: MDPI stays neutral with regard to jurisdictional claims in published maps and institutional affiliations.

Copyright: (C) 2021 by the authors Licensee MDPI, Basel, Switzerland. This article is an open access article distributed under the terms and conditions of the Creative Commons Attribution (CC BY) license (https:/ / creativecommons.org/licenses/by/ $4.0 /)$.

\begin{abstract}
Ursolic acid (UA) is a bioactive compound which has demonstrated therapeutic efficacy in a variety of cancer cell lines. UA activates various signalling pathways in Glioblastoma multiforme (GBM) and offers a promising starting point in drug discovery; however, understanding the relationship between cell death and migration has yet to be elucidated. UA induces a dose dependent cytotoxic response demonstrated by flow cytometry and biochemical cytotoxicity assays. Inhibitor and fluorescent probe studies demonstrate that UA induces a caspase independent, JNK dependent, mechanism of cell death. Migration studies established that UA inhibits GBM collective cell migration in a time dependent manner that is independent of the JNK signalling pathway. Cytotoxicity induced by UA results in the formation of acidic vesicle organelles (AVOs), speculating the activation of autophagy. However, inhibitor and spectrophotometric analysis demonstrated that autophagy was not responsible for the formation of the AVOs. Confocal microscopy and isosurface visualisation determined co-localisation of lysosomes with the previously identified AVOs, thus providing evidence that lysosomes are likely to be playing a role in UA induced cell death. Collectively, our data identify that UA rapidly induces a lysosomal associated mechanism of cell death in addition to UA acting as an inhibitor of GBM collective cell migration.
\end{abstract}

Keywords: ursolic acid; cell death; migration; lysosomes; nutraceuticals

\section{Introduction}

Glioblastoma multiforme (GBM) is a highly malignant grade IV astrocytoma. It is considered to be the most biologically aggressive brain tumour and is associated with a poor post diagnosis survival rate of about 1 year [1]. GBMs are a heterogeneous mixture of cells that display varying degrees of cellular and nuclear polymorphism, making it difficult to manage clinically. The current standard of care for GBM is maximal surgical resection followed by radiotherapy and concomitant and adjuvant chemotherapy using Temozolomide (TMZ) [2]. The efficacy of Temozolomide and radiotherapy has been limited due to treatment toxicity, therapeutic resistance and failure to successfully remove all surrounding tumour cells during surgical resection [3], therefore resulting in a high chance of tumour recurrence. Consequently, survival rates have remained relatively stagnant over the past 30 years [4]. In order to improve clinical outcomes for patients undergoing therapy, 
there is a need for the development of new therapeutic strategies that investigate alternative compounds that possess cytotoxic activity with the ability to inhibit tissue invasion.

In an effort to combat these issues, research groups have identified numerous naturally derived bioactive compounds (NDBC), known as phytochemicals, that demonstrate anticancer activity when used alone or in combination for the treatment of cancer [5]. Phytochemicals with anti-cancer properties are being assessed as precursors for new chemotherapeutic agents [6-10]. Ursolic acid (UA), a ursane-type pentacyclic triterpenoid acid, is a primary component of the thin waxy coating in popular western foods such as cranberries, apples and olives [11-14]. UA, along with other triterpenoids, has been used in Chinese Traditional Medicine for centuries to treat cancer and inflammatory disorders $[15,16]$. In recent years, UA has been shown both in vitro and in vivo to demonstrate anti-proliferative, anti-migratory, and anti-inflammatory properties and enhance the efficacy and sensitivity of chemotherapeutics in a variety of cancer types, including GBM $[17,18]$. An advantage of many naturally derived compounds such as UA is that they have the capacity to elicit a biological response while being nontoxic at low doses compared to commonly used chemotherapeutics [19], making them an ideal candidate for combinational therapy to act as a chemosensitizer. In a recent study, UA was shown to increase sensitivity to TMZ in TMZ-resistant GBM cells (T98G and LN18) in vitro [20].

UA offers a promising strategy for the treatment of GBM; however, the mechanisms of action have not been fully elucidated in the current literature. In GBM models, low concentrations of UA and natural esters of UA have been shown to inhibit the proliferation of U-87 and SF-295 cells [21,22] and prevent invasion induced by IL1 $\beta$ and TNF $\alpha$ in C6 rat glioma cells [23]. Additionally in other GBM models, UA has been shown to induce necrosis in TMZ resistant DBTRG-05MG cells [12], cell cycle arrest and autophagy in U-87 cells [24], apoptosis in U251 cells [13], and both anti-proliferative and apoptotic effects in C6 rat glioma cells in vitro [14]. It is postulated that the mechanism of cell death is cell line dependent and is likely to alter depending on the genetic mutations of the cell line. In recent years, the Nomenclature Committee on Cell Death (NCCD) has established guidelines for the interpretation cell death data [25]. In 2018, they updated the guidelines to include lysosome-dependant cell death (LDCD) and autophagy dependent cell death (ADCD). LDCD is defined as a form of regulated cell death identified lysosomal membrane permeabilization (LMP), resulting from the release of Cathepsins with or without mitochondrial outer membrane permeabilization. Autophagy, a traditionally cytoprotective process, is also recognised as a form of regulated cell death by blocking the cells cytoprotective mechanisms, therefore resulting in cell death. However, due to the involvement of lysosomes in the autophagic pathway (i.e., fusion of the lysosome with the autophagosome), LDCD can often be overlooked.

Several key questions have surfaced following observations that UA activates a variety of signalling pathways in GBM. This study carries out a direct comparison of UA with existing GBM therapies to investigate the role of UA in cell death and GBM migration with the aim of elucidating the molecular mechanisms involved in UA associated cytotoxicity.

\section{Results}

\subsection{UA Induced Cytotoxicity Results in Rapid Mitochondrial Membrane Depolarisation}

UA was found to induce rapid cytotoxicity in U-251 MG cells within $24 \mathrm{~h}$ of treatment. The rapid onset of cell death was accompanied by a characteristic, steep Hill slope, with no significant difference in $\mathrm{IC}_{50}$ values determined when cells were treated with UA for $24 \mathrm{~h}$, $48 \mathrm{~h}$ or 6 days $\left(\mathrm{R}^{2}>0.9736>0.05\right)$ (Figure $1 \mathrm{~A}$, Table S3). To help better understand UA induced cytotoxicity, two concentrations of UA (1.5 $\mu \mathrm{M}$ (Low), $\left.20 \mu \mathrm{M}\left(\mathrm{IC}_{50}\right)\right)$ or media only were chosen for evaluation using the Trypan blue cell exclusion assay $48 \mathrm{~h}$ post treatment. A significant $(p<0.0001)$ increase in the number of dead cells following treatment with UA $\mathrm{IC}_{50}$ was observed when compared to the untreated control (Figure $1 \mathrm{~b}$, left panel). When treated with low doses of UA $(1.5 \mu \mathrm{M})$, there is significant increase $(p<0.001)$ in live cell number compared to cells treated with the UA IC 50 (Figure 1B, right panel). Interestingly, 
$\mathrm{IC}_{50}$ values calculated for other carcinoma cell lines (A549 and A431) treated with UA were similar to those observed in GBM cells (Table S1).

A.

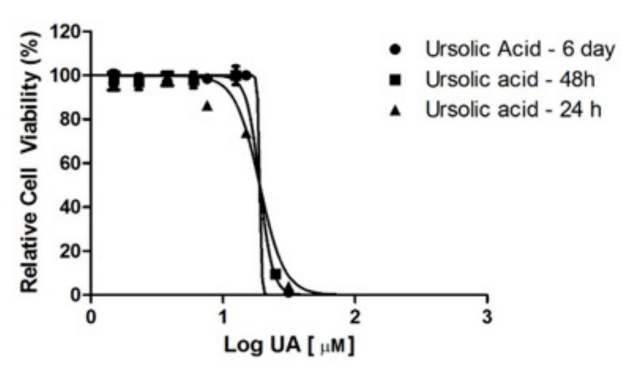

c.

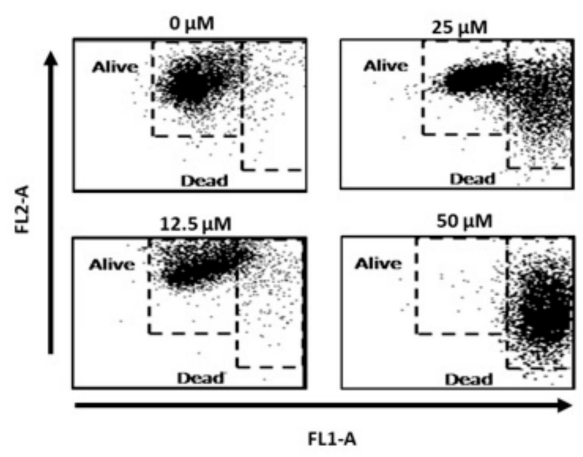

B.
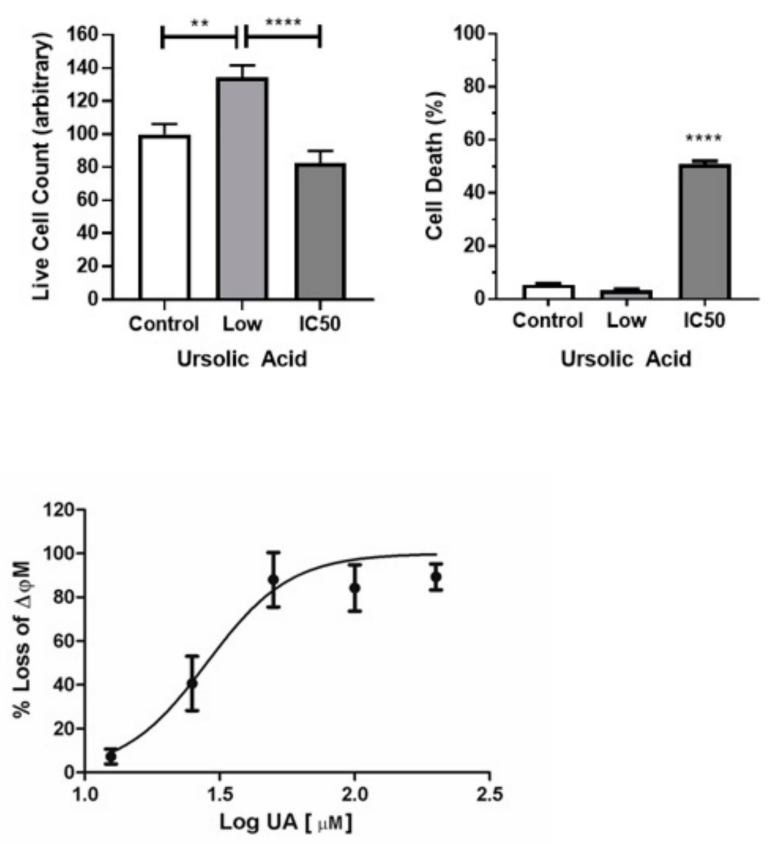

Figure 1. Ursolic acid (UA) induces mitochondrial membrane depolarisation. (A) U-251 MG cells were exposed to increasing concentrations of UA. Cell viability was assessed using Alamar blue at $24 \mathrm{~h}, 48 \mathrm{~h}$ and 6 days $(n=3)$. (B) Cells were treated with $1.5 \mu \mathrm{M}$ UA (Low), $20 \mu \mathrm{M}$ (IC50) or media only (Control) for $48 \mathrm{~h}$. Viability was measured using the Trypan blue cell exclusion assay $\left.\left.{ }^{* *} p<0.005 ;{ }^{* * *} p<0.001\right) ; n=3\right)($ C) After a $48 \mathrm{hr}$ exposure to UA, cells were loaded with $10 \mu \mathrm{g} / \mathrm{mL}$ JC-1 dye and analysed by flow cytometry. Data shown depict cell death measured by quantitative shifts in the $\Delta \Psi \mathrm{m}$ (red to green) fluorescence intensity ratio with increasing concentrations of UA $(n=3)$. Data shown were normalised to the untreated control and are shown as the \% mean \pm SEM (standard error of the mean). Statistical analysis was carried out using non-linear regression.

Mitochondrial membrane potential $(\Delta \Psi \mathrm{m})$ is an important factor of mitochondrial function and can be an indicator of early intrinsic apoptosis. Collapse of the $\Delta \Psi \mathrm{m}$ results in the release of cytochrome $C$ into the cytosol, thus leading to cell death [26]. Loss in $\Delta \Psi \mathrm{m}$ was observed following treatment with $\mathrm{UA}(p<0.05)$ in a dose dependent manner (Figure 1C, Table S4), with a significant loss at $25 \mu \mathrm{M}$ when compared to the untreated control. These data correlate with the loss of respiration function measured using Alamar blue and indicate that the depolarisation of mitochondria is an early feature of UA induced cell death.

\subsection{UA Demonstrates Enhanced Cytotoxicity Compared to Conventional Chemotherapeutic Drugs}

A comparison study was performed between UA and the standard chemotherapeutic drugs used for the treatment of GBM (TMZ) and for recurrent disease (Gefitinib and Carmustine (BCNU)). Little cytotoxicity was observed $48 \mathrm{~h}$ after treatment with Gefitinib, $\mathrm{TMZ}$ or $\mathrm{BCNU}$, which prevented $\mathrm{IC}_{50}$ values being accurately calculated. In contrast, UA demonstrated a significant reduction in cell viability $48 \mathrm{~h}$ after treatment (Figure 2A), with an $\mathrm{IC}_{50}$ value of $22 \mu \mathrm{M}$, similar to that observed in Figure 1a (Table S5). Cytotoxicity was observed 6 days post treatment using TMZ, BCNU and Gefitinib ( $\mathrm{IC}_{50}$ values were $28 \mu \mathrm{M}$, $79 \mu \mathrm{M}$ and $16 \mu \mathrm{M}$, respectively) in comparison with UA (19 $\mu \mathrm{M})$ (Figure 2B, Table S6). Interestingly, over a 6-day period only a small reduction in the $\mathrm{IC}_{50}$ value was observed. As individual agents, UA demonstrated greater cytotoxicity over a shorter period and 
at significantly lower concentrations then that used for TMZ. As demonstrated below in Figure 2C, no additive or synergistic effect was observed between low doses of TMZ and UA. It was postulated that as U-251 MG are TMZ sensitive, UA did not have a demonstrable effect on O-6-Methylguanine-DNA Methyltransferase (MGMT).

A.

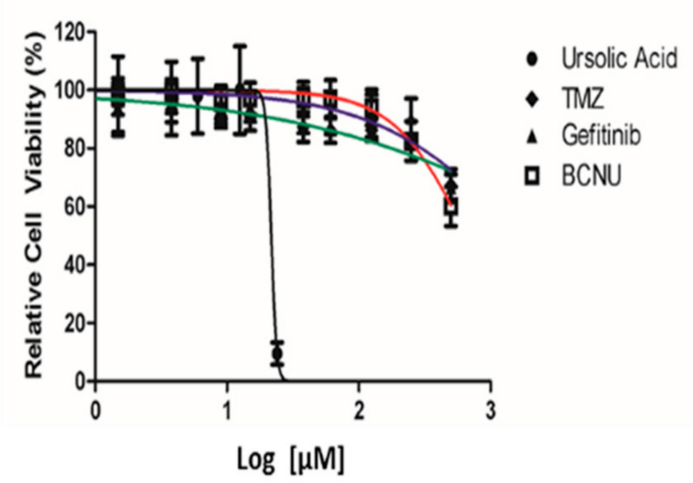

C.

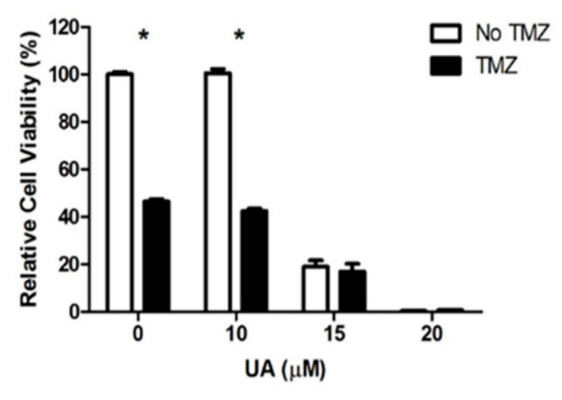

B.

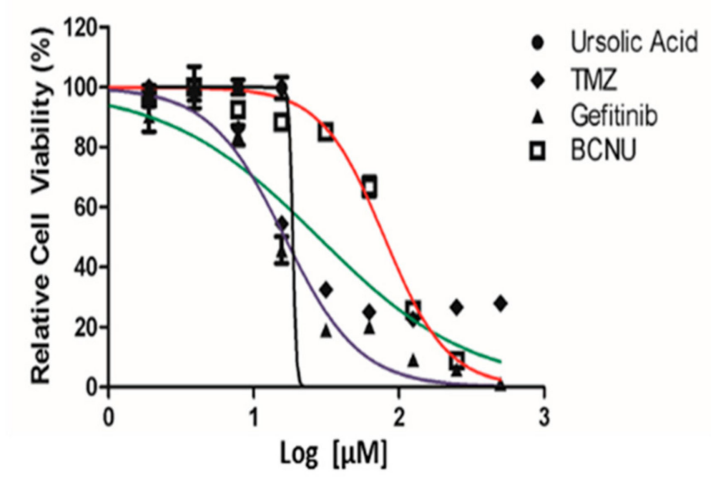

Figure 2. UA exhibits increased cytotoxicity over conventional chemotherapeutics. (A,B) U-251 MG cells were treated with increasing concentrations of UA (0-200 $\mu \mathrm{M})$, Temozolomide (TMZ), BCNU, or Gefitinib (0-500 $\mu \mathrm{M})$ for $48 \mathrm{~h}$ (A) or 6 days (B) and analysed using Alamar blue. Statistical analysis was carried out using non-linear regression analysis and Two-way ANOVA with Bonferroni post-tests, $(n=3)\left({ }^{*} p<0.001\right)$. (C) Cells were treated with $0-20 \mu \mathrm{M} \mathrm{UA}$ after which $15 \mu \mathrm{M}$ TMZ was added, incubated for 6 days and analysed by Alamar blue. Data shown were normalised to the untreated control and are shown as the $\%$ mean \pm S.E.M. Statistical analysis was carried out using Two-Way ANOVA with Bonferroni post-test $(* p<0.001)(n=3)$.

\subsection{UA Inhibits JNK-Dependent GBM Collective Cell Migration}

One of the most important hallmarks of GBM is the invasive behaviour and ability to migrate into surrounding healthy brain tissue. The scratch assay, also known as the wound healing assay, allows for preliminary quantitative characterisation of collective cell migration and screening of novel therapeutic drugs [27]. The up-regulation of the Jun $\mathrm{N}$-terminal Kinase (JNK) signalling pathway in GBM tumours is commonly associated with tumorigenesis [28] and has previously been implicated in promoting cell migration [29]. Figure 3A demonstrates that treatment of U-251 MG cells with SP600125/UA combination significantly reduced the rate of migration when compared with untreated controls $(p<0.05)$. Migration was reduced to a lesser extent when cells were treated with SP600125 alone. As previously identified above (Figure 1B), no toxicity was observed with $12.5 \mu \mathrm{M}$ UA after $24 \mathrm{~h}$; however, this may have an effect on migration signalling. Our data demonstrate that $12.5 \mu \mathrm{M}$ alone significantly reduced the rate of migration compared with the untreated control $(p<0.05$, Figure 3A). No cumulative effect was observed when UA and SP600125 were combined $(p>0.05)$, indicating a role for UA as an inhibitor of GBM collective cell migration. 
A.

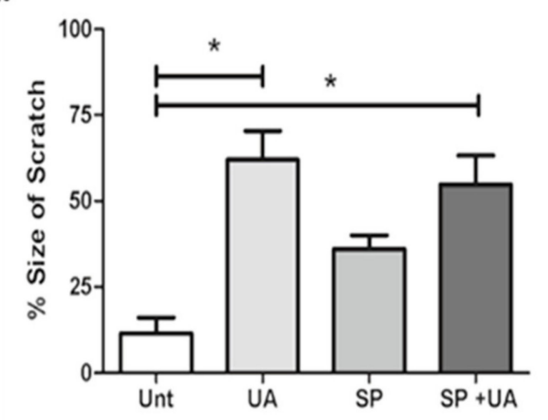

c.

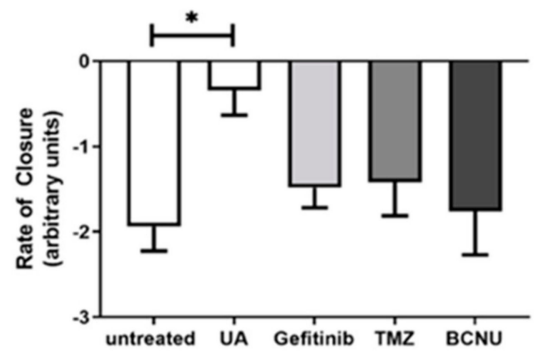

B.

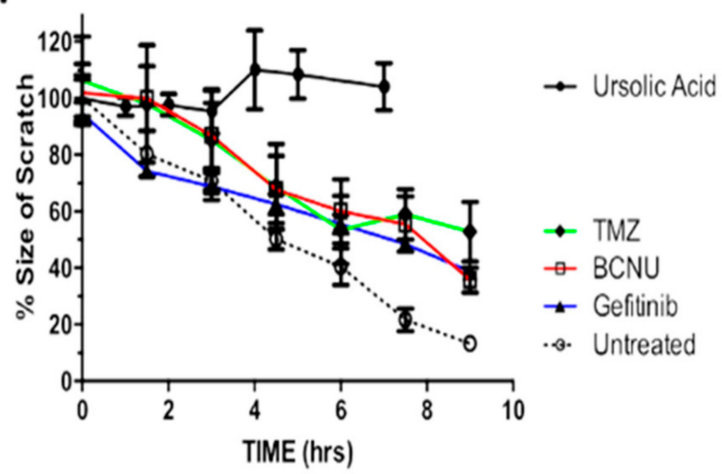

Figure 3. UA inhibits JNK-dependent Glioblastoma multiforme (GBM) collective cell migration. (A) Cells were treated with either $12.5 \mu \mathrm{M}$ UA, $12.5 \mu \mathrm{M}$ SP600125 or UA/SP combined. Images were taken at the time of the scratch and $7 \mathrm{~h}$ later. Statistical analysis was carried out using One-Way ANOVA with Tukey's multiple comparison post-test $\left({ }^{*} p<0.05\right)$ $(n=3)$. (B,C) Cells were treated with TMZ $(100 \mu \mathrm{M})$, Gefitinib $(25 \mu \mathrm{M}), \mathrm{BCNU}(50 \mu \mathrm{M}), \mathrm{UA}(12 \mu \mathrm{M})$ or were untreated. Time dependent closure of the scratch was analysed over a $9 \mathrm{~h}$ period. Statistical analysis was carried out using linear regression analysis and Two-Way ANOVA with Bonferroni post-tests. The rate of closure was determined by One-Way ANOVA with Tukey's test for multiple comparisons $(n=3)$. Image analysis was performed using ImageJ software.

The ability of UA to inhibit cell migration was compared to standard GBM chemotherapeutic drugs. The Pearson correlation coefficient, r, was calculated over the course of $9 \mathrm{~h}$ for untreated U-251 MG cells and for cells treated with sub-toxic concentrations of TMZ, BCNU, Gefitinib and UA (Figure 3B). Pearson's r was strong and negative (i.e., $r>-0.95)$ for both untreated cells and cells treated with TMZ, BCNU and Gefitinib, thus indicating that treatment with these chemotherapeutic agents did not affect the collective cell migration. Pearson's $r$ for cells treated with UA was positive, indicating that UA had completely blocked migration (Table S2). Statistical analysis confirmed that a significant level of migration was observed for untreated cells and for cells treated with TMZ, Gefitinib and BCNU ( $p<0.01$, Figure 3B), whereas no significant evidence of migration was observed for cells treated with UA $(p>0.05)$. To further examine the changes in migration following treatment with UA, the rate of scratch closure was calculated. Figure $3 \mathrm{C}$ and the associated Supplemental Movie (Video S1) of scratch closure demonstrate that the treatment of GBM cells with UA significantly $(p<0.001)$ reduces the rate of closure of the scratch when compared to the untreated control. No significance was observed for any chemotherapeutic agents when compared to untreated cells.

\subsection{UA Induces Caspase-Independent, JNK-Dependent Cell Death}

Our data indicate that an alternative mechanism of cell death may be activated following treatment with UA. Three concentrations of UA were tested in order to capture low, moderate and high degrees of cytotoxicity. The JNK specific inhibitor SP600125 alleviated cytotoxicity in U-251 MG cells induced by moderate concentrations of UA $(20 \mu \mathrm{M})$ $(p<0.001)$, with a significant increase in the $\mathrm{IC}_{50}$ value $(p<0.05)$ (Figure $\left.4 \mathrm{~A}\right)$. There was no evidence of any inhibitory effects by the broad-spectrum caspase inhibitor zVAD-fmk, as seen in Figure 4B. 
A.

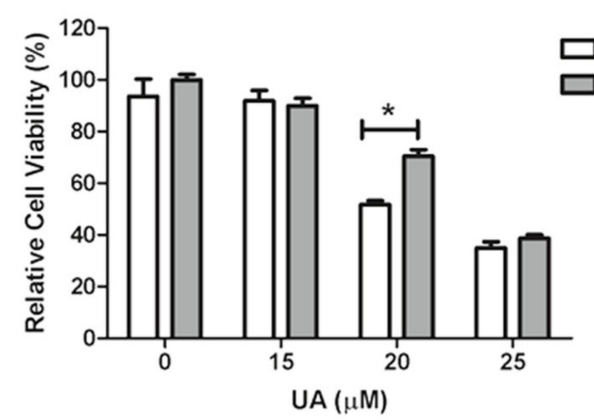

C.

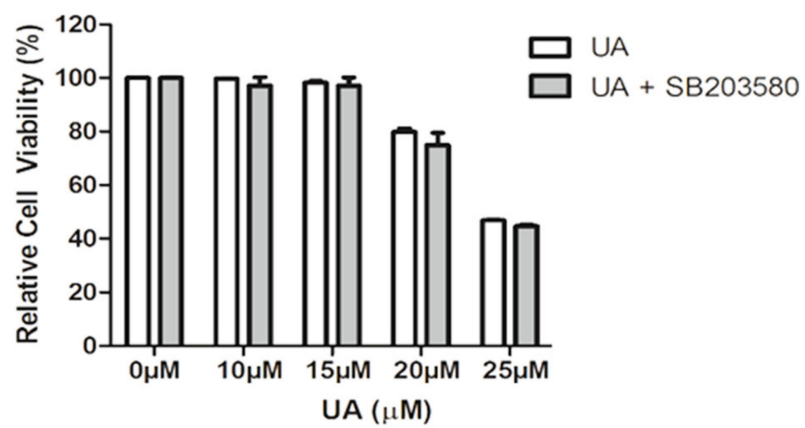

B.

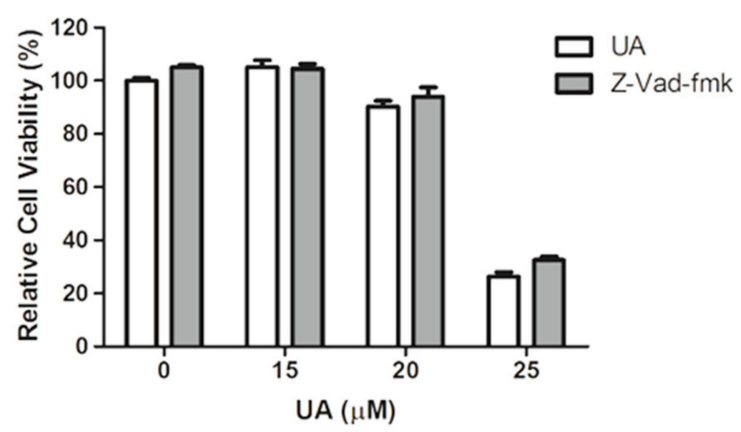

D.

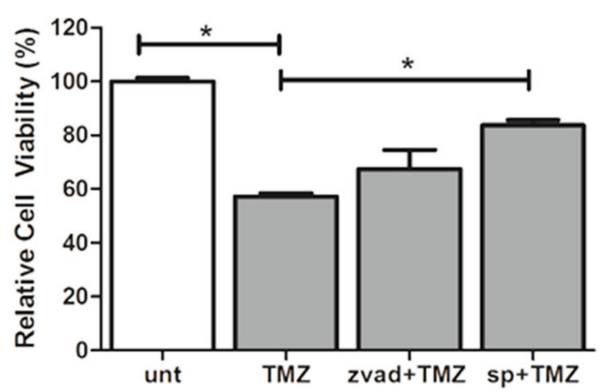

Figure 4. UA induces caspase-independent, JNK-dependent cell death. (A-C) Cells were pre-treated with either $12.5 \mu \mathrm{M}$ SP600125, $50 \mu \mathrm{M}$ zVAD-FMK or $10 \mu \mathrm{M}$ SB203580 for $1 \mathrm{~h}$. Increasing concentrations of UA were added for $48 \mathrm{~h}$ and analysed using Alamar blue. Statistical analysis was carried out using Two-Way ANOVA with Bonferroni post-test. (D) Cells were pre-treated with either zVAD-fmk $(50 \mu \mathrm{M})$ or SP600125 $(12.5 \mu \mathrm{M})$ for $1 \mathrm{~h}$ prior to addition of TMZ $(26.5 \mu \mathrm{M})$ for 6 days. Cell viability was analysed by Alamar blue. Statistical analysis was carried out using One-Way ANOVA with Tukey's post-test $\left({ }^{*} p<0.05\right)$. All experiments were normalised to untreated control and expressed as a $\%$ of the SEM $(n=3)$.

Having identified that JNK plays a role in UA induced GBM cell death, it was hypothesized whether stress-activated p38 mitogen-activated protein kinase (p38 MAPK) signalling pathways were involved. However, as demonstrated in Figure 4C, there was no evidence of any inhibitory effects by the p38 kinase inhibitor SB203580. In agreement with previous reports, Figure 4D demonstrated that JNK was involved in TMZ-induced cytotoxicity $(p<0.05)$, in contrast to this, no inhibition was observed when TMZ was combined with zVAD-fmk. These results suggest that UA induces a rapid, caspase- and p38-MAPK independent, JNK dependent mechanism of cell death in U-251 MG GBM cells that involves mitochondrial membrane depolarisation.

\subsection{UA Triggers the Formation of Lysosomes}

Autophagy is an essential cytoprotective response to pathological stressors, involving the phosphatidylinositol 3-kinase PI3K/AKT/mTOR signalling pathway, and also plays a role in tumorigenesis and invasion [30]. Having identified that UA induces cytotoxic response that is independent of caspases but dependent on JNK signalling, it was hypothesized whether autophagy was activated in response to UA treatment. Following treatment with UA, U-251 MG cells were stained with acridine orange, which is used for the detection of acidic vesicle organelles (AVOs). AVOs are deemed a significant morphological characteristic of the autophagic process [31,32]. As seen in Figure 5A, there is a significant increase in the presence of AVOs measured by quantitative shifts in the FL-2 channel (red fluorescence) intensity ratio following treatment with UA $(p<0.005)$ compared with untreated cells. This suggests the autophagy pathway may be activated during UA-induced cell death. 
A.

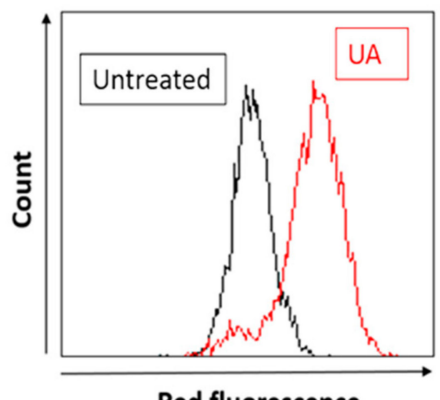

Red fluorescence

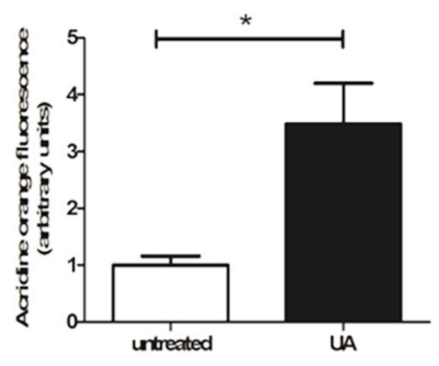

D.
B.

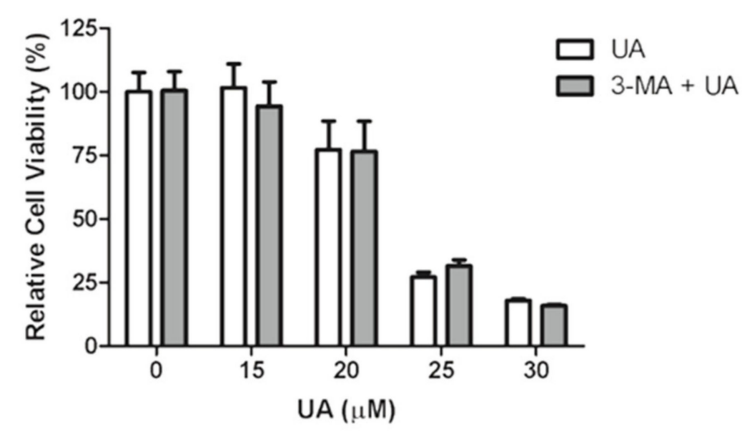

C.

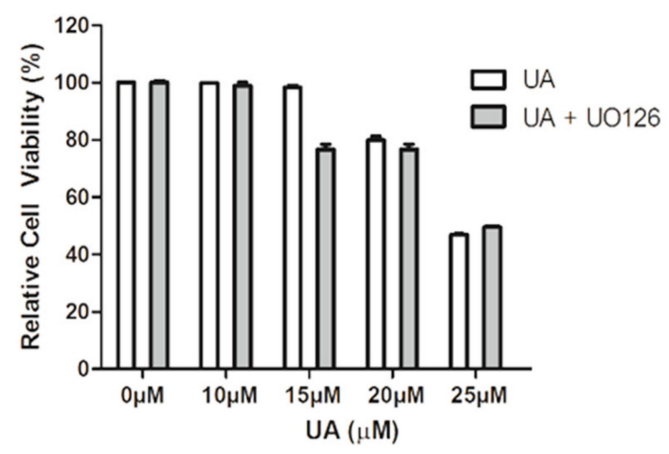

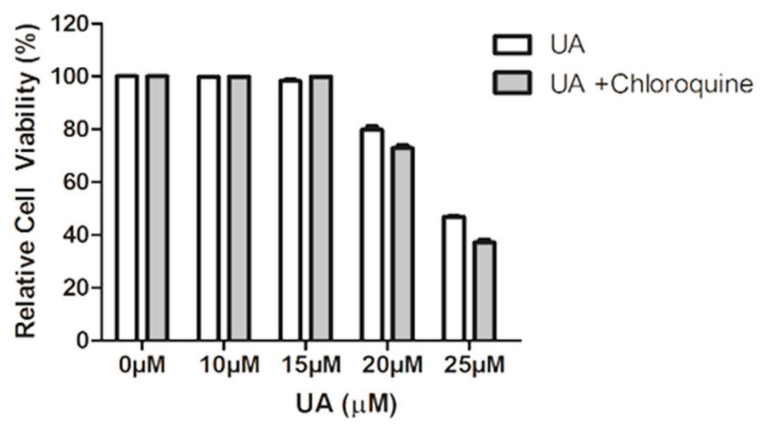

Figure 5. UA initiates formation of acidic vesicles but no evidence of autophagy. (A) U-251 MG cells were treated with $22 \mu \mathrm{M}$ UA. After $48 \mathrm{~h}$, cells were loaded with $1 \mu \mathrm{g} / \mathrm{mL}$ acridine orange fluorescent probe and analysed by flow cytometry. Data shown were normalised to the untreated control and represented as arbitrary units \pm S.E.M $(n=3)$. Quantification of mean fluorescence index and statistical analysis was performed using non-parametric t-tests $\left({ }^{*} p<0.05\right)$. (B-D) U-251 MG cells were pre-treated with $5 \mathrm{mM}$ 3-Methyladenine (3-MA), $10 \mu \mathrm{M}$ U0126, or $25 \mu \mathrm{M}$ Chloroquine for $1 \mathrm{~h}$ prior to addition of UA. Cells were incubated for $48 \mathrm{~h}$ and analysed by Alamar blue. Data shown were normalised to the untreated control and are shown as the $\%$ mean \pm S.E.M $(n=3)$. Statistical analysis was carried out using Two-Way ANOVA with Bonferroni post-test.

However, upon further investigation, no evidence of autophagy activation was identified. Furthermore, 3-MA is an inhibitor of autophagosome formation through Class III PI3K activity, which is critical for autophagy activation. As demonstrated in Figure 5B, no evidence of inhibition was observed. No inhibition of cytotoxicity was observed following the addition of U0126 inhibitor (Figure 5C), indicating that UA induced cytotoxicity is independent of Extracellular Signal-Regulated Kinase (ERK) activation. Autophagic flux is used as a measure of autophagic degradation and is associated with late stage autophagy. Cells were treated with chloroquine, a well-known inhibitor which works by destroying autophagosome and lysosome fusion [33]. Chloroquine was unable to prevent cytotoxicity induced by UA (Figure 5D).

It was postulated whether the acidic vesicles identified in Figure 5A may be an alternative acidic vesicle such as lysosomes. Figure $6 \mathrm{~A}$ demonstrates a significant increase in acidic vesicles following treatment with UA. However, when stained with lysosomal tracker deep red (Figure 6B), there is also a significant increase in fluorescence intensity following UA treatment $(p<0.0001)$. This provides evidence that the vesicles detected using (Acridine Orange) AO are lysosomes. To confirm the presence of lysosomes, 3D isosurface rendered z-stack confocal images were generated from cells treated with both AO and LysoTracker Deep Red. Figure 6C demonstrates co-localisation, as depicted in blue in the merged panel. As previously described, $\mathrm{AO}$ also binds with single-stranded nucleic 
acids and emits orange fluorescents, which can be seen in both the merged panel of the untreated control and UA treated cells [34].

A.

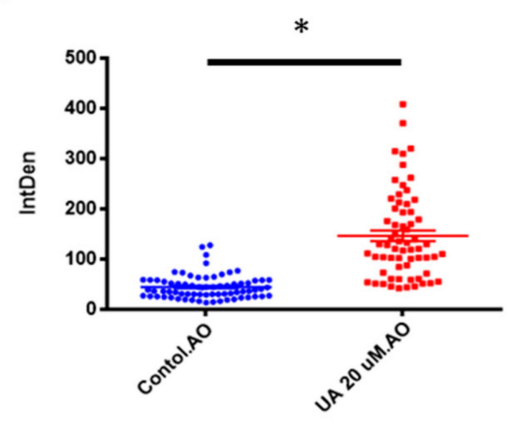

B.

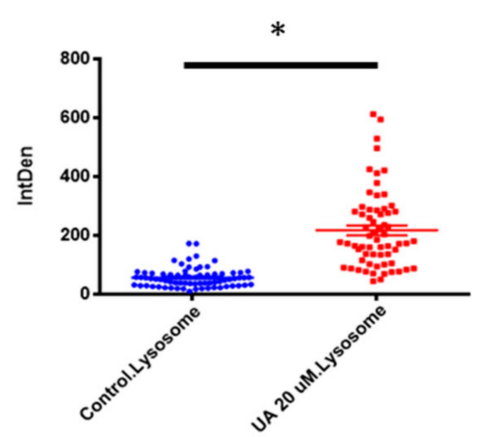

c.
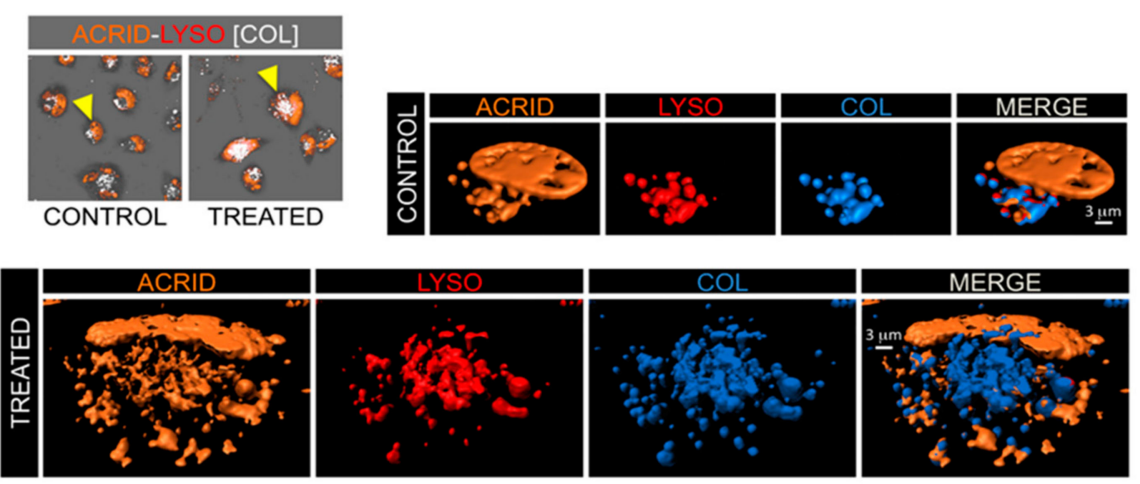

Figure 6. UA triggers lysosome accumulation. (A) U-251 MG cells were exposed to $20 \mu \mathrm{M}$ UA. After $48 \mathrm{~h}$, cells were loaded with acridine orange $\left(1 \mu \mathrm{g} / \mathrm{mL}\right.$ for $15 \mathrm{~min}$ at $\left.37^{\circ} \mathrm{C}\right)$ and (B) $50 \mathrm{nM}$ lysotracker ( $50 \mathrm{nM}$ for $30 \mathrm{~min}$ at $37^{\circ} \mathrm{C}$ ) and analysed by confocal microscopy. The fluorescence intensity of $\mathrm{AO}$ green and orange channel, and LysoTracker Deep Red was quantified using ImageJ software and compared to the untreated control. Statistical analysis was carried out using an unpaired t-test ( $\left.{ }^{*} p<0.0001\right)$. (C) Images showing co-localisation analysis of LysoTracker Deep Red (LYSO) and AO (ACRID) channels as white voxels (COL) for both control and UA treated cells. Three-dimensional visualization of control and treated cells demonstrates the co-localisation of orange (acridine orange) and red (LysoTracker Deep Red) indicated with a blue isosurface (COL) together with rendered isosurface of the AO (ACRID) and LysoTracker (LYSO) in separated channels or merged images (MERGE).

\section{Discussion}

An estimated $25 \%$ of chemotherapeutic drugs used during the last 20 years are directly derived from plants, while another $25 \%$ are chemically altered from natural products. It is noteworthy that only $5-15 \%$ of the approximately 250,000 higher plants have ever been investigated for bioactive compounds [35]. UA, found in the leaves and fruits of many plants, induces cytotoxicity in cancer cells while remaining non-toxic to normal cells [11,36]. Derivatives of UA have also demonstrated increased antitumor efficacy in vivo [37-39]. This paper demonstrates that UA induces JNK-dependent and caspase independent cytotoxicity in a human GBM model. Other groups have reported various cytotoxic and pro-survival signalling pathways activated by UA in GBM cancer cell lines, including apoptosis, autophagy, senescence and necrosis. The variability in responses observed appears partly dependent on the treatment regimen, relative resistance to TMZ and the GBM model used. Lower doses of UA were generally anti-proliferative in GBM cells without directly inducing cytotoxicity $[21,22]$. Cytotoxicity observed at higher doses of UA does not always carry the hallmark indicators of apoptosis. Biochemical indicators of apoptosis, including 
caspase activation, phosphatidylserine exposure and DNA fragmentation, were evident when TMZ-sensitive GBM cells, such as C6 cells [14] and U251 cells [13], were treated with UA in vitro. However, treatment of TMZ-resistant GBM cells with UA led to cytotoxicity associated with caspase-independent signalling, such as necrosis in DBTRG-05MG [12], LN18 and T98G cells [20]. Interestingly, in TMZ-sensitive U87MG cells, autophagy via Reactive Oxygen Species (ROS)-induced Endoplasmic Reticulum (ER) stress was reported in parallel with cytotoxicity [24]. TMZ resistance is believed to be conferred by MGMT expression in GBM cells and correlates with poor prognosis [40]. Our finding that UA induces JNK-dependent, caspase independent cytotoxicity in U-251 MG cells differs to that described in other TMZ-sensitive cell lines. UA was shown to reduce the expression of MGMT in MGMT-expressing cells and induce synergistic cytotoxicity in TMZ-resistant GBM cell lines T98G, LN18 and LN229 when co-incubated with TMZ. Moreover, the rate of tumour growth was reduced when mice challenged with flank LN18 xenograft tumours were treated with UA and TMZ [20]. We did not observe any additive or synergistic effect when U-251 MG cells were treated with a combination of TMZ and UA. This may be due to the steep Hill slope observed when U-251 MG cells were treated with UA, compared to T98G, LN18 and LN229 cells that display significant resistance to UA and TMZ, or perhaps MGMT expression in U-251 MG cells is regulated through a different UA-insensitive signal transduction pathway.

Cell migration is an important feature in many biological processes, such as tissue inflammation and tissue homeostasis, and plays a central role in cancer progression [27]. GBM is highly invasive, resulting in tumour progression and poor prognosis. Collective cell migration has been observed in many tumour types, i.e., breast [41,42]. Recent studies have also demonstrated that GBM cells and GBM cancer stem cells can migrate as both a single cell and as a collective, which is thought to influence their ability to infiltrate the surrounding tissue $[43,44]$. Therefore, it is necessary to identify novel bioactive compounds that demonstrate both anticancer and anti-migratory properties. UA has been implicated in regulating cell migration and invasion in gastric cancer cells, breast and lung cancer cells [45-47]. Oleanolic acid, a pentacyclic triterpenoid, which is structurally similar to UA differing only by the position of one methyl group on the ring E [48], has also demonstrated anti-migratory and anti-invasive effects in GBM cells by inactivating the MAPK/ERK signalling pathway [49]. Using the scratch assay, our data demonstrate that UA is a potent inhibitor of U-251 MG collective cell migration. Similarly, an investigation in human breast cancer cells found that migration was also affected through JNK, Akt and mTOR signalling following treatment with UA [46]. Interestingly, while we observed that the inhibition of JNK reduced collective cell migration, we did not observe any evidence that JNK was directly involved in the inhibition of migration following treatment with UA. The contrary appears to be the case; rather than suppression of JNK by UA, as reported by Yeh and colleagues, our data indicate that JNK activity is promoted by UA in GBM cells and mediates cytotoxicity. No adverse interaction between UA and the JNK inhibitor was observed, suggesting that UA likely affects GBM migration using a JNK-independent signalling pathway in GBM cells. Moreover, sub-toxic doses of UA were potent inhibitors of GBM collective cell migration, whereas TMZ, Gefitinib or BCNU were unable to significantly reduce collective cell migration.

Several competing hypotheses have been put forward regarding the signalling pathways responsible for UA induced cytotoxicity, with both caspases and kinases being implicated [13,50-53]. Studies to date using GBM cells suggest that caspase involvement in UA induced cell death appears to be associated with TMZ sensitivity, and observed caspase independent cell death was described as necrosis. Our data suggest that caspases are not required for UA-induced cytotoxicity in U-251 MG cells. Alternatively, our data demonstrate that JNK regulates cytotoxicity in GBM cells. No hallmarks of necrosis or necroptosis were observed, such as cell swelling and lysis, suggesting that caspase-independent apoptosis is induced by JNK in U-251 MG cells in response to UA. JNK-dependent apoptosis involving caspase activation has previously been reported for various human cancer cell lines treated 
with UA, including pancreatic [54], bladder [55] and prostate [52]. We found that UA induced JNK-dependent, caspase-independent cell death correlates with findings observed in human HCT15 colorectal cancer cells [53]. Interestingly, we found that SP600125 could significantly lower cell death at a concentration close to the $\mathrm{IC}_{50}$ of UA (i.e., $20 \mu \mathrm{M}$ ), but not at higher doses. Our observations correlate with those observed by Zhang et al. in prostate cancer cells [52] and may indicate that other cytotoxic signalling pathways can be activated by UA, depending on the cell line.

JNK activation has also been implicated during the activation of autophagy by UA. Xavier et al. reported that UA increased expression of the autophagic indicators LC3-II and P62 in colorectal carcinoma cells, which were inhibited using SP600125 [53]. Similar findings of ER stress-induced JNK activation and autophagy were reported in U-87MG cells [24]. In both studies, autophagy was associated with cell death. Similarly, Kung et al. observed UA-induced cell death without any DNA fragmentation, caspase activation or phosphatidylserine flipping in human cervical carcinoma cells, concluding that autophagy is involved in promoting UA cytotoxicity [56]. The role of autophagy in the cell death process is not fully understood. The term "autophagic cell death" was widely used in the literature, based on the observation that autophagy is commonly associated with cell stress events, and that instances of cell death accompanied by a massive cytoplasmic vacuolization lead to the conclusion that autophagy is an enabler of cell death [57]. However, recently it was noted that inhibition of the processes that are essential for cell death often does not result in inhibition of the cells' demise, but more often results in alternative biochemical pathways inducing cell death via a different mechanism [58].

Having identified the presence of AVOs by acridine orange staining, it was necessary to elucidate their identify and role in UA induced cell death. It is important to note that acridine orange cannot be used as an identifier of autophagic vesicles, but more as an indicator. Acridine orange crosses into acidic compartments and becomes protonated. Therefore, it cannot be ruled out that the observed shift in fluorescence is from the uptake of acridine orange by other acidic vesicles, such as lysosomes, and not autolysosomes. Our data demonstrated no inhibition of autophagy with the PI3 Kinase inhibitor 3-MA. Leng et al. observed a cytoprotective effect using Wortmannin (a PI3K inhibitor) and ATG5 small inhibitory RNA (siRNA) in combination with UA. However, they also observed no cytoprotective effect using PI3K inhibitor 3-MA, despite observing inhibition of LC3-II and accumulation with LY294002. Our observation that the inhibition of PI3-K using 3-MA did not alleviate the cytotoxic effects of UA correlates with Leng et al. [56]. To further confirm that autophagy was not playing a role, we observed no inhibitory effects of chloroquine on UA treated cells. Chloroquine is a lysosomotropic agent that prevents endosomal acidification and therefore inhibits autophagy as it raises the lysosomal $\mathrm{pH}$, leading to the inhibition of both the fusion of autophagosome with lysosome and lysosomal protein degradation. It was then postulated that the observed influx in acidic vesicle organelles was lysosomes, thus providing a rationale as to why no evidence of autophagy was identified. In recent years, lysosome permeabilization has been associated with cell death $[25,59,60]$. Recent data have demonstrated that another pentacyclic triterpenoid, Betulinic acid (BA), induces both mitochondrial and lysosomal dysfunction, which in turn resulted in autophagic flux inhibition [61]. Similar to our data, Martins et al. demonstrated an inhibition of cell death following co-treatment with chloroquine and BA. The authors identify that BA mediated lysosomal damage was capable of comprising autophagy, and perhaps UA is having a similar effect on lysosomes in U-251 MG treated cells. In addition, a similar effect was also observed following exposure of NH2-PS nanoparticles to mouse embryonic fibroblasts, where after an $8 \mathrm{hr}$ exposure, autophagic flux was blocked due to damage to the lysosomes resulting in LDCD [59]. Interestingly, Martins et al. also demonstrated that cell death following BA was associated with both lysosome damage and mitochondrial depolarisation. In this study, our data show rapid depolarisation of the mitochondria following treatment with UA. It is possible that due to the steep cytotoxic Hill slope, the rapid depolarisation of the mitochondria and clear evidence of lysosome 
accumulation, UA induces physiological stress, to the point that autophagy was unable to return to and maintain homeostasis, therefore resulting in lysosome associated cell death.

Together, this study demonstrates that UA has a greater capacity to induce cell death and inhibit GBM collective cell migration over currently used chemotherapeutic agents, demonstrating efficacy as a potential therapeutic target. Based on our findings that UA induces a JNK regulated form of cell death that results in the rapid depolarisation of the mitochondria and the accumulation of lysosomes, it is plausible that LDCD may be playing a role. However, further investigation is required to fully elucidate whether lysosomes are damaged following treatment with UA, similarly to that observed with other triterpenoids.

\section{Materials and Methods}

\subsection{Cell Culture}

Human glioblastoma U-251 MG, formerly known as U-373 MG (ECACC 09063001)), cells were obtained from Dr Michael Carty (Trinity College Dublin). U-251 MG cells were cultured in Dulbecco's Modified Eagle Medium (DMEM) (Sigma-Aldrich, Arklow, Ireland) supplemented with 10\% Fetal bovine serum (FBS) (Sigma-Aldrich, Arklow, Ireland) and were maintained in a humidified incubator containing $5 \% \mathrm{CO}_{2}$ at $37{ }^{\circ} \mathrm{C}$. Media were changed every 2-3 days until 80\% confluency was reached. Cells were routinely subcultured using a final 1:1 ratio of 0.25\% trypsin (Sigma-Aldrich, Arklow, Ireland) and 0.1\% Ethylenediaminetetraacetic acid (EDTA) (Sigma-Aldrich, Arklow, Ireland).

\subsection{Cytotoxicity}

Dose response curves for commonly employed chemotherapeutic drugs used for the treatment of GBM: Temozolomide (TMZ) (Sigma-Aldrich, Arklow, Ireland), Carmustine (BCNU) (Sigma-Aldrich, Arklow, Ireland) and Gefitinib (Insight Biotechnology ltd, Wembley, UK) UA standard (Sigma-Aldrich, Arklow, Ireland) were established. UA standard, TMZ and Gefitinib were dissolved in Dimethyl sulfoxide (DMSO) (Sigma-Aldrich, Arklow, Ireland) and $\mathrm{BCNU}$ in sterile $\mathrm{H}_{2} \mathrm{O}$ and stored at $-20^{\circ} \mathrm{C}$. These stocks were subsequently used to make the working standard solutions in media. The highest concentration of DMSO used was 0.5\%. U-251 MG cells were seeded at a density of $1 \times 10^{4}(24$ and $48 \mathrm{hr}$ exposure time points) in 96 well plates (Sigma-Aldrich, Arklow, Ireland) with $100 \mu \mathrm{L}$ media per well. In order to establish accurate $\mathrm{IC}_{50}$ values for the chemotherapeutic compounds, a lower seeding density of $2.5 \times 10^{3}$ and a 6 -day exposure period were required. Plates were left overnight in the incubator at $37^{\circ} \mathrm{C}$ with $5 \% \mathrm{CO}_{2}$ to allow the cells to adhere. Existing media were removed from each well and cells were treated with either a chemotherapeutic drug, UA or solvent control (0.5\% DMSO) and incubated for the appropriate time point. No deleterious effects were observed from the control solvent.

\subsection{Cell Viability Assays}

Trypan blue cell exclusion assay was performed as an initial evaluation of cell health following treatment with UA. Cell were trypsinized as described above. A Trypan Blue (Fischer Scientific, Ballycoolin, Ireland) cell suspension was counted using a haemocytometer as per manufacturer's instructions. Cell viability was also measured biochemically using the Alamar Blue assay (Fischer Scientific, Ballycoolin, Ireland). Alamar blue is an oxidation-reduction (redox) fluorogenic indicator of cellular metabolic reduction. After each exposure time point, $(24 \mathrm{~h}$ or $48 \mathrm{~h}$ ) cells were washed once with sterile Phosphatebuffered saline (PBS). A 10\% Alamar blue solution in the DMEM was added to each well and incubated at $37^{\circ} \mathrm{C}$ for $2.5 \mathrm{~h}$. Fluorescence was read at an excitation wavelength of $530 \mathrm{~nm}$ and an emission wavelength of $595 \mathrm{~nm}$ using the Victor 3V 1420 (Perkin Elmer) multi-plate reader. 


\subsection{Flow Cytometry}

\subsubsection{JC-1 Mitochondrial Membrane Potential Assay}

As described above, cells were plated and exposed to varying concentrations of UA for $48 \mathrm{~h}$. Cells were then harvested and stained with $10 \mu \mathrm{g} / \mathrm{mL}$ JC-1 dye, a mitochondrial membrane potential probe (Biosciences, Dublin, Ireland) (Galluzzi et al., 2007), at room temperature for $10 \mathrm{~min}$ and analysed by flow cytometry (BD Accuri C6). JC-1 was excited using the argon laser at a wavelength of $488 \mathrm{~nm}$. Fluorescence was measured using the FL1 $(530 \mathrm{~nm})$ and FL2 $(585 \mathrm{~nm})$ channels with emission spectral overlap compensation $(7.5 \%$ FL1/FL2 and 15\% FL2/FL1).

\subsubsection{Acridine Orange (AO)}

Cells were harvested and stained with $1 \mu \mathrm{g} / \mathrm{mL}$ AO and incubated at $37^{\circ} \mathrm{C}$ for $20 \mathrm{~min}$. Cells were then washed twice with sterile PBS and analysed by flow cytometry (BD Accuri C6) with an excitation of $475 \mathrm{~nm}$ and emission $590 \mathrm{~nm}$. Detection of AVOs was achieved using the FL1 (green) vs. FL2 (orange) channels and compensation was set at approximately $7 \%$ removing FL2 signal from FL1 and approximately 16\% removing FL1 signal from FL2 for each plot.

\subsection{Scratch Assay}

The scratch assay allows for the preliminary examination of the effects of TMZ, Gefitinib, BCNU, and UA on the migration of U-251 MG cells. Cells were treated with each compound, at a sub-toxic concentration, to prevent cytotoxic responses but potentially inhibit migration. U-251 MG cells were seeded at $0.9 \times 10^{6}$ cells in individual $35 \mathrm{~mm}$ dishes and incubated for $24 \mathrm{~h}$. A scratch was performed in each dish prior to treatment using a $200 \mu \mathrm{L}$ sterile pipette tip. Utilising the data observed from the UA dose response curve, a sub-toxic concentration $(12 \mu \mathrm{M})$ was chosen. Cells were treated with either media alone, DMSO $(0.1 \%)$, or $12.5 \mu \mathrm{M} \mathrm{UA}$, each scratch was examined under a light microscope and images were taken using the (Nikon Eclipse 700). Multiple images were taken for each time point and the average size of scratch for that time point was obtained. Image analysis was performed using image processing and analysis software, Image J [62].

\subsection{Inhibitor Studies}

U-251 MG Cells were plated in 96 well plates as described above and left to adhere overnight. Cells were pre-treated for $1 \mathrm{~h}$ with either zVAD-FMK; caspase inhibitor (BD Bioscience, Oxford, England), SP600125; JNK inhibitor, SB203580; p38 MAP Kinase Inhibitor (Sigma Aldrich, Arklow, Ireland), U0126; MEK1 and MEK2 Kinase Inhibitor (Sigma Aldrich, Arklow, Ireland), chloroquine or 3-methyladenine (3-MA), autophagy inhibitors (Sigma Aldrich, Arklow, Ireland) after which the UA standard (IC50) was added to each well. Cell viability was assessed $48 \mathrm{~h}$ later using Alamar Blue cell viability assay.

\subsection{Confocal Microscopy}

U-251 MG cells were plated in $35 \mathrm{~mm}$ glass bottom dishes (MatTek Corporation, Ashland Massachusetts, USA) at $1 \times 10^{5}$ cells per $\mathrm{ml}$ and incubated for $24 \mathrm{~h}$. Cells were treated with $20 \mu \mathrm{M} \mathrm{UA}$ for $48 \mathrm{~h}$. After treatment, cells were loaded with AO $(1 \mu \mathrm{g} / \mathrm{mL}$ for $15 \mathrm{~min}$ at $37^{\circ} \mathrm{C}$ ) and LysoTracker Deep Red (Thermo Fisher Scientific) (50 nM for $30 \mathrm{~min}$ at $37^{\circ} \mathrm{C}$ ). Images were captured on a Zeiss $510 \mathrm{LZSM}$ confocal inverted microscope. The corresponding filter settings were as follows: AO, excitation $477 \mathrm{~nm}$, emission $585-615 \mathrm{~nm}$; LysoTracker Deep Red, excitation 633 nm, emission 649-799 nm. All images were taken using live cells. The total integrated density of fluorescence of each cell was quantified using ImageJ (v1.49, NIH) software. The quantified integrated density equals to the sum of the pixel values in the selected fluorescent area. 


\subsection{Isosurface Rendering}

Representative confocal Z-scans of U-251 MG cells were processed for a three-dimensional reconstruction and visualization of volumetric co-localization of the acidic vesicles (ACRID) and lysosomes (LYSO). Fluorescent ACRID-LYSO colocalizing voxels were detected by a computerized software using Coloc module (Imaris Bitplane, South Windsor, CT, USA), then a new channel with these voxels was extracted. Then, this colocalizing voxels channel was used to generate a three-dimensional isosurface employing Surface module (Imaris BitPlane, South Windsor, CT, USA) with the appropriate threshold and resolution. Similarly, ACRID and LYSO channels were also used to generate three-dimensional renderings as isosurfaces. Merging of the volumetric isosurfaces was set to illustrate the degree of colocalizing objects in control and treated glioma cells. Adequate shadowing and angle of three-dimensional rotation was applied to show the relevant cellular structures.

\subsection{Statistical Analysis}

All experiments were performed in triplicate, independently of each other with a minimum of five replicates per experiment. Data shown are pooled and presented as mean \pm SEM ( $n=$ total number of replicates) unless stated otherwise. Statistical analysis was performed using Prism 5, GraphPad Software, Inc. (San Diego, CA, USA). Unless otherwise indicated, differences were considered significant with $\mathrm{a}^{*} p$ value $<0.05$.

Supplementary Materials: The following are available online at https:/ /www.mdpi.com/1424-824 7/14/2/91/s1, Table S1: Cytotoxic evaluation of UA in carcinoma cell lines, Table S2: Investigation of the effect of UA on U-251 MG collective cell migration. Tables S3-S6 IC50 values for Figures 1a,c and 2a,b. Video S1: UA scratch closure over time.

Author Contributions: G.E.C., O.H. and J.F.C. conceptualized the paper. G.E.C., D.Z., J.R.M.M., Z.H., L.L and M.L., performed the experiments, collected and analysed the data. C.B. processed the images for deconvolution and generated the 3D isosurfaces rendering. G.E.C., D.Z., J.R.M.M., Z.H., L.L, M.L., J.F.C. co-wrote the paper. All authors have read and agreed to the published version of the manuscript.

Funding: This work is supported by the Irish Research Council IRCSET grant (G.E.C), Spanish Ministry of Economy and Competitiveness and European Regional Development Fund Grant number SAF2015-64123-P (C.B. and G.P.C).

Data Availability Statement: The authors will freely release all data underlying the published paper upon direct request to the corresponding author.

Acknowledgments: The authors also thank the FOCAS Research Institute, TU Dublin and Institut de Neurociències at UAB for the use of facilities. The graphical abstract was created using BioRender.com software.

Conflicts of Interest: The authors declare no conflict of interest.
Abbreviations
GBM Glioblastoma multiforme
UA Ursolic Acid
AVOs Acidic vesicle organelles
TMZ Temozolomide
NDBC Naturally derived bioactive compound
NCCD Nomenclature Committee on Cell Death
LDCD Lysosome-dependant cell death
ADCD Autophagy dependent cell death
AO Acridine orange
3-MA 3-methyladenine 


\section{References}

1. Philips, A.; Henshaw, D.L.; Lamburn, G.; O'Carroll, M.J. Brain tumours: Rise in glioblastoma multiforme incidence in England 1995-2015 suggests an adverse environmental or lifestyle factor. J. Environ. Public Health 2018, 2018. [CrossRef]

2. Adamson, C.; Kanu, O.O.; Mehta, A.I.; Di, C.; Lin, N.; Mattox, A.K.; Bigner, D.D. Glioblastoma multiforme: A review of where we have been and where we are going. Expert Opin. Investig. Drugs 2009, 18, 1061-1083. [CrossRef]

3. Candolfi, M.; Curtin, J.F.; Nichols, W.S.; Muhammad, A.G.; King, G.D.; Pluhar, G.E.; McNiel, E.A.; Ohlfest, J.R.; Freese, A.B.; Moore, P.F.; et al. Intracranial glioblastoma models in preclinical neuro-oncology: Neuropathological characterization and tumor progression. J. Neurooncol. 2007, 85, 133-148. [CrossRef]

4. Nørøxe, D.S.; Poulsen, H.S.; Lassen, U. Hallmarks of glioblastoma: A systematic review. ESMO Open 2016, 1, 1. [CrossRef]

5. Salim, S.; Snape, T.; Welsby, P.; Welsby, G. Phytochemicals-An alternative therapy for glioblastoma? Neuro. Oncol. 2018, 20, i5. [CrossRef]

6. Øverby, A.; Zhao, C.-M.; Chen, D. Plant phytochemicals: Potential anticancer agents against gastric cancer. Curr. Opin. Pharmacol. 2014, 19, 6-10. [CrossRef]

7. Koldaş, S.; Demirtas, I.; Ozen, T.; Demirci, M.A.; Behçet, L. Phytochemical screening, anticancer and antioxidant activities of Origanum vulgare L. ssp. viride (Boiss.) Hayek, a plant of traditional usage. J. Sci. Food Agric. 2015, 95, 786-798. [CrossRef]

8. Neto, C.C. Cranberry and its phytochemicals: A review of in vitro anticancer studies. J. Nutr. 2007, 137, 186S-193S. [CrossRef]

9. Sasidharan, S.; Chen, Y.; Saravanan, D.; Sundram, K.M.; Yoga-Latha, L. Extraction, isolation and characterization of bioactive compounds from plants' extracts. Afr. J. Tradit. Complement. Altern. Med. 2011, 8, 1-10. [CrossRef]

10. Wang, H.; Khor, T.O.; Shu, L.; Su, Z.-Y.; Fuentes, F.; Lee, J.-H.; Kong, A.-N.T. Plants vs. cancer: A review on natural phytochemicals in preventing and treating cancers and their druggability. Anti Cancer Agents Med. Chem. 2012, 12, 1281-1305. [CrossRef] [PubMed]

11. Shanmugam, M.K.; Dai, X.; Kumar, A.P.; Tan, B.K.H.; Sethi, G.; Bishayee, A. Ursolic acid in cancer prevention and treatment: Molecular targets, pharmacokinetics and clinical studies. Biochem. Pharmacol. 2013, 85, 1579-1587. [CrossRef] [PubMed]

12. Lu, C.-C.; Huang, B.-R.; Liao, P.-J.; Yen, G.-C. Ursolic acid triggers nonprogrammed death (necrosis) in human glioblastoma multiforme DBTRG-05MG cells through MPT pore opening and ATP decline. Mol. Nutr. Food Res. 2014, 58, 2146-2156. [CrossRef] [PubMed]

13. Wang, J.; Li, Y.; Wang, X.; Jiang, C. Ursolic acid inhibits proliferation and induces apoptosis in human glioblastoma cell lines U251 by suppressing TGF- $\beta 1 / \mathrm{miR}-21 /$ PDCD4 pathway. Basic Clin. Pharmacol. Toxicol. 2012, 111, 106-112. [CrossRef] [PubMed]

14. Bergamin, L.S.; Figueiró, F.; Dietrich, F.; de Manica, F.; Filippi-Chiela, E.C.; Mendes, F.B.; Jandrey, E.H.F.; Lopes, D.V.; Oliveira, F.H.; Nascimento, I.C.; et al. Interference of ursolic acid treatment with glioma growth: An in vitro and in vivo study. Eur. J. Pharmacol. 2017, 811. [CrossRef] [PubMed]

15. Huang, M.T.; Ho, C.T.; Yuan-Wang, Z.; Ferraro, T.; Lou, Y.R.; Stauber, K.; Ma, W.; Georgiadis, C.; Laskin, J.D.; Conney, A.H. Inhibition of skin tumorigenesis by rosemary and its constituents carnosol and ursolic acid. Cancer Res. 1994, 54, 701-708. [PubMed]

16. Petiwala, S.M.; Puthenveetil, A.G.; Johnson, J.J. Polyphenols from the Mediterranean herb rosemary (Rosmarinus officinalis) for prostate cancer. Front. Pharmacol. 2013, 4, 29. [CrossRef] [PubMed]

17. Navin, R.; Mi Kim, S. Therapeutic interventions using ursolic acid for cancer treatment. Med. Chem. 2016, 6. [CrossRef]

18. Woźniak, Ł.; Skąpska, S.; Marszałek, K. Ursolic acid-A pentacyclic triterpenoid with a wide spectrum of pharmacological activities. Molecules 2015, 20, 20614-20641. [CrossRef] [PubMed]

19. Kotecha, R.; Takami, A.; Espinoza, J.L. Dietary phytochemicals and cancer chemoprevention: A review of the clinical evidence. Oncotarget 2016, 7, 52517-52529. [CrossRef] [PubMed]

20. Zhu, Z.; Du, S.; Ding, F.; Guo, S.; Ying, G.; Yan, Z. Ursolic acid attenuates temozolomide resistance in glioblastoma cells by downregulating O(6)-methylguanine-DNA methyltransferase (MGMT) expression. Am. J. Transl. Res. 2016, 8, 3299-3308. [PubMed]

21. Bonaccorsi, I.; Altieri, F.; Sciamanna, I.; Oricchio, E.; Grillo, C.; Contartese, G.; Galati, E.M. Endogenous reverse transcriptase as a mediator of ursolic acid's anti-proliferative and differentiating effects in human cancer cell lines. Cancer Lett. 2008, 263, 130-139. [CrossRef] [PubMed]

22. Kondo, M.; Mackinnon, S.L.; Craft, C.C.; Matchett, M.D.; Hurta, R.A.R.; Neto, C.C. Ursolic acid and its esters: Occurrence in cranberries and other Vaccinium fruit and effects on matrix metalloproteinase activity in DU145 prostate tumor cells. J. Sci. Food Agric. 2011, 91, 789-796. [CrossRef] [PubMed]

23. Huang, H.-C.; Huang, C.-Y.; Lin-Shiau, S.-Y.; Lin, J.-K. Ursolic acid inhibits IL-1beta or TNF-alpha-induced C6 glioma invasion through suppressing the association ZIP/p62 with PKC-zeta and downregulating the MMP-9 expression. Mol. Carcinog. 2009, 48, 517-531. [CrossRef] [PubMed]

24. Shen, S.; Zhang, Y.; Zhang, R.; Tu, X.; Gong, X. Ursolic acid induces autophagy in U87MG cells via ROS-dependent endoplasmic reticulum stress. Chem. Biol. Interact. 2014, 218, 28-41. [CrossRef] [PubMed]

25. Galluzzi, L.; Vitale, I.; Aaronson, S.A.; Abrams, J.M.; Adam, D.; Agostinis, P.; Alnemri, E.S.; Altucci, L.; Amelio, I.; Andrews, D.W.; et al. Molecular mechanisms of cell death: Recommendations of the nomenclature committee on cell death 2018. Cell Death Differ. 2018, 25, 486-541. [CrossRef] [PubMed]

26. Salido, M.; Gonzalez, J.L.; Vilches, J. Loss of mitochondrial membrane potential is inhibited by bombesin in etoposide-induced apoptosis in PC-3 prostate carcinoma cells. Mol. Cancer Ther. 2007, 6, 1292-1299. [CrossRef] 
27. Pijuan, J.; Barceló, C.; Moreno, D.F.; Maiques, O.; Sisó, P.; Marti, R.M.; Macià, A.; Panosa, A. In vitro cell migration, invasion, and adhesion assays: From cell imaging to data analysis. Front. Cell Dev. Biol. 2019, 7, 107. [CrossRef]

28. Portela, M.; Venkataramani, V.; Fahey-Lozano, N.; Seco, E.; Losada-Perez, M.; Winkler, F.; Casas-Tintó, S. Glioblastoma cells vampirize WNT from neurons and trigger a JNK/MMP signaling loop that enhances glioblastoma progression and neurodegeneration. PLoS Biol. 2019, 17, e3000545. [CrossRef]

29. Zhou, X.; Hua, L.; Zhang, W.; Zhu, M.; Shi, Q.; Li, F.; Zhang, L.; Song, C.; Yu, R. FRK controls migration and invasion of human glioma cells by regulating JNK/c-Jun signaling. J. Neurooncol. 2012, 110, 9-19. [CrossRef]

30. Murrow, L.; Debnath, J. Autophagy as a stress-response and quality-control mechanism: Implications for cell injury and human disease. Annu. Rev. Pathol. Mech. Dis. 2013, 8, 105-137. [CrossRef]

31. Paglin, S.; Hollister, T.; Delohery, T.; Hackett, N.; McMahill, M.; Sphicas, E.; Domingo, D.; Yahalom, J. A Novel response of cancer cells to radiation involves autophagy and formation of acidic vesicles. Cancer Res. 2001, 61, 439-444. [PubMed]

32. Shin, S.W.; Kim, S.Y.; Park, J.-W. Autophagy inhibition enhances ursolic acid-induced apoptosis in PC3 cells. Biochim. Biophys. Acta Mol. Cell Res. 2012, 1823, 451-457. [CrossRef] [PubMed]

33. Mauthe, M.; Orhon, I.; Rocchi, C.; Zhou, X.; Luhr, M.; Hijlkema, K.J.; Coppes, R.P.; Engedal, N.; Mari, M.; Reggiori, F. Chloroquine inhibits autophagic flux by decreasing autophagosome-lysosome fusion. Autophagy 2018, 14, 1435-1455. [CrossRef]

34. Conway, G.E.; He, Z.; Hutanu, A.L.; Cribaro, G.P.; Manaloto, E.; Casey, A.; Traynor, D.; Milosavljevic, V.; Howe, O.; Barcia, C.; et al. Cold atmospheric plasma induces accumulation of lysosomes and caspase-independent cell death in U373MG glioblastoma multiforme cells. Sci. Rep. 2019, 9. [CrossRef] [PubMed]

35. Amin, A.; Gali-Muhtasib, H.; Ocker, M.; Schneider-Stock, R. Overview of major classes of plant-derived anticancer drugs. Int. J. Biomed. Sci. 2009, 5, 1-11.

36. Weng, H.; Tan, Z.; Hu, Y.; Shu, Y.; Bao, R.; Jiang, L.; Wu, X. Ursolic acid induces cell cycle arrest and apoptosis of gallbladder carcinoma cells. Cancer Cell Int. 2014, 14, 1-10. [CrossRef]

37. Wang, X.; Zhang, F.; Yang, L.; Mei, Y.; Long, H.; Zhang, X.; Zhang, J.; Qimuge-Suyila, S.; Su, X. Ursolic acid inhibits proliferation and induces apoptosis of cancer cells in vitro and in vivo. J. Biomed. Biotechnol. 2011, 2011, 419343. [CrossRef]

38. Zhang, H.; Zheng, D.; Ding, J.; Xu, H.; Li, X.; Sun, W. Efficient delivery of ursolic acid by poly(N-vinylpyrrolidone)-block-poly ( $\varepsilon$-caprolactone) nanoparticles for inhibiting the growth of hepatocellular carcinoma in vitro and in vivo. Int. J. Nanomed. 2015, 10, 1909-1920. [CrossRef]

39. Yoon, Y.; Lim, J.W.; Kim, J.; Kim, Y.; Chun, K.H. Discovery of ursolic acid prodrug (NX-201): Pharmacokinetics and in vivo antitumor effects in PANC-1 pancreatic cancer. Bioorganic Med. Chem. Lett. 2016, 26, 5524-5527. [CrossRef]

40. Hermisson, M.; Klumpp, A.; Wick, W.; Wischhusen, J.; Nagel, G.; Roos, W.; Kaina, B.; Weller, M. O6-methylguanine DNA methyltransferase and p53 status predict temozolomide sensitivity in human malignant glioma cells. J. Neurochem. 2006, 96, 766-776. [CrossRef]

41. Cheung, K.J.; Ewald, A.J. A collective route to metastasis: Seeding by tumor cell clusters. Science 2016, 352, 167-169. [CrossRef] [PubMed]

42. Khalil, A.A.; Ilina, O.; Gritsenko, P.G.; Bult, P.; Span, P.N.; Friedl, P. Collective invasion in ductal and lobular breast cancer associates with distant metastasis. Clin. Exp. Metastasis 2017, 34, 421-429. [CrossRef] [PubMed]

43. Volovetz, J.; Berezovsky, A.D.; Alban, T.; Chen, Y.; Lauko, A.; Aranjuez, G.F.; Burtscher, A.; Shibuya, K.; Silver, D.J.; Peterson, J.; et al. Identifying conserved molecular targets required for cell migration of glioblastoma cancer stem cells. Cell Death Dis. 2020, 11, 1-12. [CrossRef] [PubMed]

44. Alieva, M.; Leidgens, V.; Riemenschneider, M.J.; Klein, C.A.; Hau, P.; van Rheenen, J. Intravital imaging of glioma border morphology reveals distinctive cellular dynamics and contribution to tumor cell invasion. Sci. Rep. 2019, 9, 2054. [CrossRef]

45. Kim, E.-S.E.; Moon, A. Ursolic acid inhibits the invasive phenotype of SNU-484 human gastric cancer cells. Oncol. Lett. 2015, 9, 897-902. [CrossRef] [PubMed]

46. Yeh, C.-T.T.; Wu, C.-H.H.; Yen, G.-C.C. Ursolic acid, a naturally occurring triterpenoid, suppresses migration and invasion of human breast cancer cells by modulating c-Jun N-terminal kinase, Akt and mammalian target of rapamycin signaling. Mol. Nutr. Food Res. 2010, 54, 1285-1295. [CrossRef]

47. Huang, C.-Y.; Lin, C.-Y.; Tsai, C.-W.; Yin, M.-C. Inhibition of cell proliferation, invasion and migration by ursolic acid in human lung cancer cell lines. Toxicol. In Vitro 2011, 25, 1274-1280. [CrossRef] [PubMed]

48. Ovesná, Z.; Kozics, K.; Slamenová, D. Protective effects of ursolic acid and oleanolic acid in leukemic cells. Mutat. Res. 2006, 600, 131-137. [CrossRef]

49. Guo, G.; Yao, W.; Zhang, Q.; Bo, Y. Oleanolic acid suppresses migration and invasion of malignant glioma cells by inactivating MAPK/ERK signaling pathway. PLoS ONE 2013, 8, e72079. [CrossRef]

50. Kassi, E.; Papoutsi, Z.; Pratsinis, H.; Aligiannis, N.; Manoussakis, M.; Moutsatsou, P. Ursolic acid, a naturally occurring triterpenoid, demonstrates anticancer activity on human prostate cancer cells. J. Cancer Res. Clin. Oncol. 2007, 133, 493-500. [CrossRef]

51. Gao, N.; Cheng, S.; Budhraja, A.; Gao, Z.; Chen, J.; Liu, E.-H.; Huang, C.; Chen, D.; Yang, Z.; Liu, Q.; et al. Ursolic acid induces apoptosis in human leukaemia cells and exhibits anti-leukaemic activity in nude mice through the PKB pathway. Br. J. Pharmacol. 2012, 165, 1813-1826. [CrossRef] [PubMed] 
52. Zhang, Y.; Kong, C.; Zeng, Y.; Wang, L.; Li, Z.; Wang, H.; Xu, C.; Sun, Y. Ursolic acid induces PC-3 cell apoptosis via activation of JNK and inhibition of Akt pathways in vitro. Mol. Carcinog. 2010, 49, 374-385. [CrossRef]

53. Xavier, C.P.R.; Lima, C.F.; Pedro, D.F.N.; Wilson, J.M.; Kristiansen, K.; Pereira-Wilson, C. Ursolic acid induces cell death and modulates autophagy through JNK pathway in apoptosis-resistant colorectal cancer cells. J. Nutr. Biochem. 2013, 24, 706-712. [CrossRef]

54. Liang, X. Ursolic acid inhibits growth and induces apoptosis in gemcitabine-resistant human pancreatic cancer via the JNK and PI3K/Akt/NF-kB pathways. Oncol. Rep. 2012. [CrossRef]

55. Zheng, Q.; Li, P.; Jin, F.; Yao, C.; Zhang, G.; Zang, T.; Ai, X. Ursolic acid induces ER stress response to activate ASK1-JNK signaling and induce apoptosis in human bladder cancer T24 cells. Cell. Signal. 2013, 25, 206-213. [CrossRef] [PubMed]

56. Leng, S.; Hao, Y.; Du, D.; Xie, S.; Hong, L.; Gu, H.; Zhu, X.; Zhang, J.; Fan, D.; Kung, H. Ursolic acid promotes cancer cell death by inducing Atg5-dependent autophagy. Int. J. Cancer 2013, 133, 2781-2790. [CrossRef] [PubMed]

57. Galluzzi, L.; Vitale, I.; Abrams, J.M.; Alnemri, E.S.; Baehrecke, E.H.; Blagosklonny, M.V.; Dawson, T.M.; Dawson, V.L.; El-Deiry, W.S.; Fulda, S.; et al. Molecular definitions of cell death subroutines: Recommendations of the Nomenclature Committee on Cell Death 2012. Cell Death Differ. 2012, 19, 107-120. [CrossRef]

58. Galluzzi, L.; Bravo-San Pedro, J.M.; Vitale, I.; Aaronson, S.A.; Abrams, J.M.; Adam, D.; Alnemri, E.S.; Altucci, L.; Andrews, D.; Annicchiarico-Petruzzelli, M.; et al. Essential versus accessory aspects of cell death: Recommendations of the NCCD 2015. Cell Death Differ. 2015, 22, 58-73. [CrossRef]

59. Boya, P.; Wang, F.; Salvati, A.; Boya, P. Lysosome-dependent cell death and deregulated autophagy induced by amine-modified polystyrene nanoparticles. Open Biol. 2018, 4. [CrossRef]

60. Wang, F.; Gómez-Sintes, R.; Boya, P. Lysosomal membrane permeabilization and cell death. Traffic 2018, 19, 918-931. [CrossRef]

61. Martins, W.K.; Costa, É.T.; Cruz, M.C.; Stolf, B.S.; Miotto, R.; Cordeiro, R.M.; Baptista, M.S. Parallel damage in mitochondrial and lysosomal compartments promotes efficient cell death with autophagy: The case of the pentacyclic triterpenoids. Sci. Rep. 2015, 5 . [CrossRef] [PubMed]

62. Schneider, C.A.; Rasband, W.S.; Eliceiri, K.W. NIH image to imageJ: 25 years of image analysis. Nat. Methods 2012, 9, 671-675. [CrossRef] [PubMed] 